\title{
Is Routine Dissection of Level II-B and V-A Necessary in Patients with Papillary Thyroid Cancer Undergoing Lateral Neck Dissection for FNA-Confirmed Metastases in Other Levels
}

\author{
Sudhi Agarwal · Gyan Chand - Amit Agarwal • \\ Anjali Mishra • Gaurav Agarwal • A. K. Verma • \\ S. K. Mishra
}

Published online: 29 January 2010

(C) Société Internationale de Chirurgie 2010

We read with interest the article by Farrag et al. [1] published in the August 2009 issue and want to congratulate them for their highly informative effort. Spinal accessory nerve (SAN) injury been addressed by various thyroid and cancer surgeons [2], as it may lead to shoulder syndrome, which has a profound effect on the patient's quality of life. It is also important in cases of cancers with relatively good prognosis, where other adjuvant treatment options following neck dissection for head and neck malignancies are available in the form of radioactive iodine ablation. Therefore, the risk of level IIb and Va lymph node metastasis must be weighed against the risk of SAN injury following dissection at these levels. Lee et al. [3] did the first prospective study in this regard and found that the anterolateral group were at greatest risk of lymphatic metastasis. In addition, level IIb lymph nodes metastasis was found only in association with level IIa metastasis. Similar evaluations performed retrospectively by others found similar results $[4,5]$.

However, we would like to gain some clarity from the authors about the exact levels of lymph nodes found positive on fine-needle aspiration cytology or peroperatively and their correlation with the level IIb lymph nodes, as the incidence of skip metastasis and multiple level disease is significantly high for papillary thyroid cancer [4, 5]. We also want to know the exact numbers, the levels of lymph nodes dissected, and the histopathologic features of the primary tumor and the metastatic lymph nodes as these data may also throw more light on the risk of involvement of level IIb lymph nodes.

\section{References}

1. Farrag T, Lin F, Brownlee $\mathrm{N}$ et al (2009) Is routine dissection of level II-B and V-A necessary in patients with papillary thyroid cancer undergoing lateral neck dissection for FNA-confirmed metastases in other levels. World J Surg 33:1680-1683

2. Nilakantan A (2006) Preservation of spinal accessory nerve during radical neck dissection. Med J Armed Forces India 62:131-133

3. Lee J, Sung TY, Nam KH et al (2008) Is level IIb lymph node dissection always necessary in N1b papillary thyroid carcinoma patients? World J Surg 32:716-721

4. Roh JL, Kim JM, Park CI et al (2008) Lateral cervical lymph node metastases from papillary thyroid carcinoma: pattern of nodal metastases and optimal strategy for neck dissection. Ann Surg Oncol 15:1177-1182

5. Koo BS, Yoon YH, Kim JM et al (2009) Predictive factors of level IIb lymph node metastasis in patients with papillary thyroid carcinomas. Ann Surg Oncol 16:1344-1347
S. Agarwal $(\bowtie) \cdot$ G. Chand · A. Agarwal · A. Mishra

G. Agarwal · A. K. Verma - S. K. Mishra

Department of Endocrine Surgery, Sanjay Gandhi Post Graduate Institute of Medical Sciences, Raebareli Road, Lucknow 226014, India

e-mail: sudhi@sgpgi.ac.in 